\title{
Genetic Heterogeneity in Colorectal Cancer and its Clinical Implications
}

\author{
Heterogeneidade Genética no Cancro Colorrectal e as suas Implicações \\ Clínicas
}

Rui BARRANHA $\triangle^{1,2}$, José Luís COSTA², Fátima CARNEIRO ${ }^{1,2,3}$, José Carlos MACHADO ${ }^{1,2}$ Acta Med Port 2015 May-Jun;28(3):370-375

\section{ABSTRACT}

Despite the recent advances in the development of complementary diagnostic exams and modern targeted therapies, colorectal cancer remains a major cause of morbidity and mortality worldwide. In this context, a lot of research has been conducted in the last years to find new markers of poor prognosis. The existence of a complex tumour architecture formed by multiple subclones genetically heterogeneous has been increasingly considered in recent studies as an element of particular importance. This feature seems to influence factors as relevant as the representativeness of tumour biopsies for genetic diagnosis and the efficacy of targeted therapies. There is growing evidence suggesting a relation between genetic heterogeneity and the patients' prognosis. The widespread use of next-generation sequencing techniques will allow a better understanding of the true degree of genetic heterogeneity in colorectal tumours, its causes and impact on the course of the disease. In this review we intend to analyse the recent findings related to the genetic heterogeneity of colorectal cancer, as well as its major clinical implications.

Keywords: Colorectal Neoplasms/genetics; Genetic Heterogeneity; Molecular Targeted Therapy; Translational Medical Research.

\section{RESUMO}

Apesar dos recentes avanços no desenvolvimento de métodos complementares de diagnóstico e de novas terapêuticas dirigidas, o cancro colo-rectal continua a ser uma importante causa mundial de morbilidade e mortalidade. Neste sentido, têm sido desenvolvidos nos últimos anos inúmeros trabalhos de investigação com o intuito de encontrar possíveis marcadores de mau prognóstico ainda não caracterizados. A existência de uma arquitectura tumoral complexa formada por vários subclones com heterogeneidade genética entre si tem sido consistentemente apontada em linhas de investigação recentes como um elemento de particular importância. Esta característica parece ter implicações em factores tão relevantes como a representatividade da amostragem tumoral de biópsias para diagnóstico genético e a eficácia de terapias dirigidas, existindo um crescente grau de evidência da relação entre a heterogeneidade genética e o prognóstico dos doentes. O uso generalizado de técnicas de sequenciação de nova geração irá permitir uma melhor compreensão do verdadeiro grau de heterogeneidade genética dos tumores colo-rectais, das suas causas e do seu real impacto na evolução da doença. Nesta revisão pretendemos analisar as recentes descobertas relacionadas com a heterogeneidade genética do cancro colo-rectal, bem como as suas principais implicações clínicas.

Palavras-chave: Heterogeneidade Genética; Investigação Médica Translacional; Neoplasias Colo-Rectais/genética; Terapia Molecular Dirigida.

\section{INTRODUCTION}

Colorectal cancer is an important cause of global morbidity and mortality. Its aetiology is related to sporadic and hereditary genetic alterations in connection with environmental factors, such as dietary composition. ${ }^{1}$ According to statistics from the International Agency for Research on Cancer through the GLOBOCAN series, colorectal cancer is the third most frequent type of cancer in men (approximately $10.0 \%$ of all cancers) and the second in women $(9.2 \%$ of total) worldwide, with the majority of cases taking place in developed countries. ${ }^{2}$ In 2012 this neoplasm was responsible for 694,000 deaths, ${ }^{2}$ being its mortality correlated with the stage of the cancer at the moment of diagnosis. Data from the American Cancer Society shows that the five-year survival rate in colorectal cancers diagnosed at a localized stage is about $90 \%$, whereas cancers with distant metastases at diagnosis see their rate drop to $13 \% .^{3}$ Such values highlight the importance

of implementing national screening programs for the early detection of colorectal cancers, whose advantages for the population health have been confirmed in several studies. ${ }^{4}$

Despite the development of modern diagnostic and treatment technologies as well as advances in pharmacogenomics, colorectal cancer is still a major burden worldwide. Therefore, it becomes imperative to continually improve our understanding of the mechanisms underlying carcinogenic and cancer drug resistance processes in order to prevent, control and cure increasingly more cancers. In this context, genetic tumour heterogeneity has been reported in recent years as a potentially relevant factor to consider in cancer research. It may be implicated in aspects as important as clinical outcome and resistance to therapies. In this review we intend to analyse the latest findings related to genetic heterogeneity, with particular attention to colorectal cancer, and its major clinical implications.

\footnotetext{
1. Department of Pathology and Oncology. Faculdade de Medicina. Universidade do Porto. Porto. Portugal.

2. Instituto de Patologia Molecular e Imunologia. Universidade do Porto (IPATIMUP). Porto. Portugal.

3. Department of Pathology. Hospital de S. João. Porto. Portugal.

$\bowtie$ Autor correspondente: Rui Barranha. ruibarranha@gmail.com

Recebido: 03 de Abril de 2014 - Aceite: 31 de Julho de 2014 | Copyright @ Ordem dos Médicos 2015
} 


\section{Tumour heterogeneity}

The existence of phenotypic heterogeneity and nuclear pleomorphism within a tumour has been observed in the nineteenth century with the advent of microscopic diagnosis and the classification of cancers by pathologists. ${ }^{5}$ Nowadays, due to this intra-tumour diversity it is common practice among pathologists to evaluate several samples of one tumour, attributing it the highest grade observed. ${ }^{6}$ In fact, it has been considered for some time that cancers are originated from distinct subclones that accumulate somatic mutations and are subjected to Darwinian processes of natural selection. ${ }^{7}$ Recent studies have confirmed the existence of independent evolution of clones in the colon as soon as the stage of microadenoma and throughout adenoma development until the adenoma-to-carcinoma transition, ${ }^{8}$ suggesting that colorectal tumorigenesis is a process characterised by polyclonality and a branched evolution of clones. This eventually originates the emergence of a complex tumour architecture constituted by intermingled genetically distinct clones. ${ }^{9}$ In terms of DNA copy number, it has been demonstrated that such intratumour heterogeneity can mirror the level of heterogeneity between different tumours. ${ }^{10}$ However, as far as genetic variability is concerned, the degree of heterogeneity within individual tumours does not display such extreme values, as will be posteriorly outlined.

There has been accumulating evidence reinforcing this concept of branched evolution in solid tumours, ${ }^{11-13}$ which can be understood as the existence of several niches of cells developing strategies to increase their fitness to survive in a potentially adverse environment. As a matter of fact, the ability to resist cell death by apoptosis has been established as one of the hallmarks of cancer. ${ }^{14}$ While the majority of premalignant cells are removed through the apoptotic machinery, some neoplastic cells avoid being eliminated by increasing their mutation rate and accumulating random mutations. ${ }^{15}$ This increase in the mutational load may grant them characteristics that will make them more fit to confront the pressures of natural selection ${ }^{16}$ and may lead to the emergence of clones with increased proliferative advantage. ${ }^{16}$ Nonetheless, most cancer cells do not develop such advantages and eventually die before dividing, which partially explains the fact that tumours' doubling time are usually much longer than the cancer cell cycle time. ${ }^{9}$

The existence of genomic instability is likely to be a significant cause of genetic heterogeneity as well. Indeed its exact impact might be underestimated due to the impossibility of evaluating the mutational landscape of every single tumour cell. ${ }^{17}$ Nevertheless, it must be taken into account that different instability mechanisms are related to distinct patient outcomes. Specifically, colorectal tumours with microsatellite instability correlate with good clinical prognosis. ${ }^{17}$ There is not a definite explanation for this fact. However, it has been reported that microsatellite instability may lead to the creation of neoantigens that induce the formation of immune infiltrates. ${ }^{17,18}$ The accumulation of T-cells in colorectal cancer has been reported to be associated with better clinical prognosis. ${ }^{19}$

\section{Genetic heterogeneity between primary tumours and metastases}

In addition to the presence of heterogeneity between subclones of a primary tumour it is important to bear in mind the possible existence of genetic heterogeneity between primary tumours and its related metastases. Such a finding can happen in case the metastases are originated from a minor subclone not easily detected in biopsy samples of the primary tumour or in view of a parallel progression model of the metastases in relation to the primary tumour. ${ }^{20}$ In fact, some minor subclones might have a higher ability to metastasize than the majority of other cells in the primary tumour. This can lead to the selection of a specific mutational load in the metastases and thus to a certain degree of heterogeneity. ${ }^{21}$

One important feature that may also play a significant role in the development of this kind of genetic heterogeneity is the microenvironment. ${ }^{22,23}$ In order to adapt to a dynamic microenvironment, the tumour may need to change its genetic composition both at different times and locations. ${ }^{6,21}$ Moreover, the fact that the microenvironment in which the primary tumour and its metastasis are located might be different could lead to the outgrowth of metastatic cells with a mutational load distinct from the primary tumours, as a way to adapt to different selection pressures. ${ }^{16}$ The stroma and the vascular supply are two environmental factors particularly relevant in the development of a tumour mass that may display significant variations between different locations, thereby inducing the emergence of genetic heterogeneity between primary tumours and its associated metastases. ${ }^{18}$ The stroma is nowadays recognized as an important part of tumours, making it necessary to approach cancers as functional organs and not just a group of neoplastic cells. ${ }^{18}$ In fact, cancer-associated fibroblasts have characteristics that differentiate them from regular fibroblasts, ${ }^{18}$ and may act as a relevant factor in treatment response. ${ }^{24}$ Moreover, it is believed that minor subclones can interact with other subclones through the release of paracrine factors that induce their growth, maintaining the intra-tumour heterogeneity ${ }^{25}$ and reinforcing the idea that tumours are more than just a mass of cells.

The distribution of tumour vessels is also an important cause of tumour heterogeneity. Regions of hypoxia within a tumour or a metastasis are a source of selective pressure that can induce the emergence of clones harbouring mutations that grant them survival advantages. ${ }^{18}$ Furthermore, the tumour vasculature is also a determining factor in the diffusion of chemotherapy agents, ${ }^{26}$ affecting the clinical outcome in colorectal cancer. ${ }^{27}$ Hypoxic regions may actually protect colon cancer stem cells from chemotherapy. ${ }^{28}$ It has also been shown that endothelial cells have paracrine effects on neoplastic cells, inducing cancer stem cell-like phenotype on colorectal cancer cells, thereby increasing chemoresistance. ${ }^{29}$ The importance of the vascular supply to colorectal cancer is supported by the 
fact that the use of bevacizumab, a monoclonal antibody directed against vascular endothelial growth factor (VEGF), has positive effects in the treatment of metastatic colorectal cancer. ${ }^{30}$

\section{The effect of genetic heterogeneity on tumour sampling}

The previously described causes of tumour heterogeneity impose relevant questions related to whether or not biopsy samples are illustrative of the overall genetic content of tumours. When it is necessary to evaluate the presence of mutations in a tumour the clinical routine is to study the mutational status of only one neoplastic location. Until this moment there is no formal indication as to which samples are more adequate to be tested: primary tumour, lymph nodal or distant metastases. Nevertheless, there have been recent findings regarding genetic heterogeneity in colorectal cancer that must be taken into account in the future.

First of all, the presence of intra-tumour heterogeneity may be responsible for the existence of contradictory results in the mutation analysis of resected tumours when compared with biopsies. Although recent studies have demonstrated that biopsy samples are 'sufficiently representative' 31 of the whole tumour and that they can be used with efficacy in clinical practice, ${ }^{31,32}$ it has been estimated that using only a tumour sample will eventually misdiagnose $7 \%$ of patients as wild-type for KRAS, making it imperative to analyse the cost-effectiveness of using more than one biopsy. ${ }^{33}$ In order to reduce the probability of sampling bias, radiologic models to assess the presence of intra-tumour genetic heterogeneity are being developed. ${ }^{34}$

Secondly, it has been found that the tumour centre has a higher rate of KRAS mutations when compared to its invasion front ${ }^{35}$. Moreover, recent data suggested that lymph nodal metastases are not as suitable as primary tumour samples and distant metastases to assess the mutational status of a neoplastic disease $\mathrm{e}^{35}$ as they have an inferior and more heterogeneous amount of mutations. ${ }^{35,36}$ In fact, it has been proposed that nodal metastases could be originated in a disease stage prior to the acquisition of KRAS mutations by primary tumours. ${ }^{36}$

Finally, in case of a clinical relapse the usual procedure is to take into consideration the mutational status of biopsies previously obtained. Nevertheless, these results may not correspond to the mutations present in the tumour after treatment or disease progression. ${ }^{37}$ Therefore, performing new biopsies could be important to direct treatments in such cases. $^{37}$

\section{The impact of genetic heterogeneity on targeted therapies}

It could be particularly relevant to determine the full extent of genetic heterogeneity in every patient's cancer because even a small degree of mutational discordance between primary tumours and metastases may lead to an unreliable diagnosis and misselection of treatments. With the advent of personalized medicine there has been an increasing interest in the research and clinical use of therapies molecularly directed to specific targets. This is the case of monoclonal antibodies to epidermal growth factor receptor (EGFR), cetuximab and panitumumab, in colorectal cancer. ${ }^{38}$ These antibodies are approved for the treatment of KRAS wild-type metastatic colorectal cancer, and they were the first treatment for solid tumours whose approval depends on a genetic test. ${ }^{38}$

In fact, it has been shown in several studies that only patients with wild-type KRAS have substantial clinical response rates (up to $50 \%$ of all patients), while patients with KRAS mutated tumours only have effective responses in a maximum of $6 \%$ of all cases. ${ }^{39-43}$ Although only KRAS and NRAS mutations are used routinely as exclusion criteria for the use of anti-EGFR monoclonal antibodies, mutations in other EGFR-dependent signalling molecules may induce resistance to the treatment. It has been estimated that it would be possible to identify up to $15 \%$ more refractory cases to this treatment if mutation analyses for BRAF and PIK3CA was to be introduced in clinical practice. ${ }^{35}$ Despite what could be expected, the expression levels of EGFR do not seem to have a predictive value in the therapeutic response to these antibodies. ${ }^{44,45}$ As a matter of fact, it has been found that tumours classified as EGFR-negative by immunohistochemistry have the potential to respond in up to $25 \%$ of all cases. ${ }^{46}$ Such findings could, however, be explained by the existence of intra-tumour heterogeneity that leads to sampling bias.

Directed therapies are regularly planned according to the analysis of primary tumour samples' mutational status. Nevertheless, there is increasing evidence of clonal diversity between metastatic and primary tumour samples, which translates in suboptimal treatment of metastatic disease. ${ }^{16}$ Many studies have reported incongruous determinations of prognostic or predictive biomarkers between primary tumours and distant metastases in several tumour models. However, the average degree of heterogeneity is difficult to estimate with accuracy because of methodological and sampling limitations. Specifically in colorectal cancer, the values of disparity for KRAS mutations (used as a predictive biomarker of response to directed therapies) between primary tumours and metastases in different studies has ranged from $0 \%$ to $60 \% .{ }^{47}$ Some of the studies that found a substantially high value of discrepancy in the mutational status of primary tumours and metastases have led to the suggestion that distant metastases should be preferentially studied when the use of targeted therapies is being considered. ${ }^{21}$ This procedure is, however, associated with higher risk of complications and is not usually performed in clinical practice. On the other hand, there is an increasing number of recent studies reporting a degree of concordance between primary tumours and metastases higher than $95 \%,{ }^{21,48-52}$ one of these studies using next-generation sequencing techniques. Therefore, it has been proposed that the metastases should only be biopsied in patients with more than one primary cancer. ${ }^{50}$

A better understanding of the mechanisms that induce 
tumour heterogeneity could improve the management of cancer patients and probably help to predict treatment resistance. Some mechanisms of therapeutic resistance are well defined and involve secondary genetic alterations that restrict the binding of drugs to their targets or induce the activation of alternative pathways. ${ }^{16,20}$ However, many mutations that induce resistance to targeted therapies may exist prior to the start of the treatment in minor subclones. Those may emerge and become dominant due to the selective pressures of such therapies. ${ }^{20}$ In the case of colorectal cancer, circulating DNA tumour with KRAS mutations can be detected in some patients 5 to 6 months after treatment with anti-EGFR antibody therapy, ${ }^{53}$ reinforcing the possible existence prior to treatment of minor subclones harbouring mutations that induce resistance to directed therapies.

Therefore, the degree of genetic diversity between tumour cells could be fairly informative and if properly measured this information could be used with therapeutic advantage. The 'trunk-branch model' of tumour heterogeneity, documented by Gerlinger et al, ${ }^{12}$ demonstrates that 'driver mutations' in the trunk are the ones for which treatments could be directed and that could be used as valuable predictive biomarkers with eventually less sampling bias, considering that they should be present in all tumour cells. ${ }^{6}$ Nevertheless, the minor subpopulations, that form the branches, harbour mutations that induce resistance and may lead to treatment failure. ${ }^{6}$

It is also striking that the effects of targeted therapies in the clonal composition of tumours might provide some evidences on the existence of genetic heterogeneity. In fact, the isolated use of cetuximab without any concomitant cytotoxic chemotherapy induces the emergence of KRAS mutations. ${ }^{54}$ Such mutations can be detected in plasma up to 10 months prior to imaging confirmation of the evolution of metastatic disease. ${ }^{54}$ Due to this, the initial clinical response to targeted therapies can be followed by disease progression. The selective pressure induced by these treatments may benefit the growth of pre-existent KRAS mutated clones (undetectable before treatment) or the development of de novo mutations as a consequence of neoplastic mechanisms to avoid cell death. Additionally, in some tumours that fail to respond to treatment with antiEGFR antibodies (being originally considered candidates for such therapy after being classified as KRAS wild-type by Sanger sequencing) further analysis using more sensitive techniques ultimately identified mutations. ${ }^{55}$

In the near future of personalized medicine, the improvement of sequencing technologies will allow the detection of mutations only expressed by a minority of cells before the start of treatment and will eventually lead to the use of a combination of successful therapies, targeting multiple signalling pathways simultaneously. Besides, developing techniques to analyse cell-free circulating tumour DNA and circulating tumour cells would allow an early detection of resistance and relapse to therapies, as well as changes in the overall clonal composition of tumours. ${ }^{37}$
Despite the fact that the implementation of that kind of personalized medicine still falls short of what was expected a few years ago, the use of targeted therapies has increased in several types of cancer such as colorectal, breast and lung cancers as well as lymphoma, melanoma and gastrointestinal stromal tumours. There has also been a diversification in the targeted cellular pathways and molecules. An illustrative example of this are the varied approaches in terms of drugs and biomarkers in the treatment of non-small-cell lung carcinoma. ${ }^{56}$ It is currently approved in this disease the use of erlotinib and gefitinib (directed against EGFR), as well as crizotinib (an ALK inhibitor). Moreover, studies are being conducted to evaluate the clinical potential of therapies targeting the immune system of patients with this type of cancer. ${ }^{56}$ Examples of this are ipilimumab (anti-CTLA-4 antibody) and nivolumab (anti-PD-1 antibody). Hopefully, in colorectal cancer there will be similar advances in the near future in the design of drugs directed against different signalling pathways or other target molecules.

\section{Future challenges}

The vast majority of advanced and metastatic cancers are still incurable despite the remarkable advances in translational and clinical research in the last decades. The introduction of molecular-targeted drugs has considerably enhanced the outcome of patients with solid tumours in advanced stages. However, not all molecularly selected patients will demonstrate clinical benefit and some of them will fail to respond to the therapy. Besides, even some patients who initially respond to targeted treatments often relapse due to the emergence of drug resistance.

Along with the development of next-generation sequencing techniques, the possibility of identifying mutations that are only expressed in minor clones, and therefore less represented in the whole tumour, is gradually becoming a reality. ${ }^{16}$ This way it will be possible to effectively assess the overall mutational landscape of tumours in the near future ${ }^{57}$ thus increasing our ability to evaluate the degree of intra and inter-tumour heterogeneity of a single patient. ${ }^{6}$ In order to ensure the reliability of results achieved through these techniques the Next Generation Sequencing Standardization of Clinical Testing workgroup advocates that all mutations with clinical implications should be corroborated by alternative methods. ${ }^{58}$ However, in the case of low-frequency mutations representative of minor subclones, it might not be possible to do so by Sanger or PCR sequencing. ${ }^{37}$ Furthermore, such procedure poses a problem related to how long do oncologists and patients consider adequate to wait for the result of genetic diagnostics before initiating a treatment. ${ }^{37}$

Finally, there is an issue that must be considered when conducting research to assess intra-tumour heterogeneity. Transplantation assays in animal models have been used in several studies to examine genetic heterogeneity in different types of cancer and have generated numerous and sometimes contradictory results. However, such 
reports must be cautiously interpreted considering that they may possibly not resemble with accuracy what happens in human tumours. ${ }^{59}$ In fact, xenotransplanted tumours might not express to the full extent their growth potential due to mice's immune system response ${ }^{59}$ and may also not recreate the structure of functional tissues due to inadequate stromal environment. ${ }^{59}$ For all this, the results produced in studies about intra-tumour heterogeneity should be critically analysed for potential biases in their design, as it may lead to erroneous conclusions.

\section{PROTECTION OF HUMANS AND ANIMALS}

The authors declare that the procedures were followed according to the regulations established by the Clinical

\section{REFERENCES}

1. Cunningham D, Atkin W, Lenz HJ, Lynch HT, Minsky B, Nordlinger B, et al. Colorectal cancer. Lancet. 2010;375:1030-47.

2. GLOBOCAN 2012. Estimated Cancer Incidence, Mortality and Prevalence Worldwide in 2012. [accessed 2014 Jan 19]. Available from: http://globocan.iarc.fr/.

3. Siegel R, Ma J, Zou Z, Jemal A. Cancer statistics, 2014. CA Cancer J Clin. 2014;64:9-29.

4. Smith RA, Manassaram-Baptiste D, Brooks D, Cokkinides V, Doroshenk M, Saslow D, et al. Cancer screening in the United States, 2014: a review of current American Cancer Society guidelines and current issues in cancer screening. CA Cancer J Clin. 2014;64:30-51.

5. Hajdu SI. A note from history: landmarks in history of cancer, part 3. Cancer. 2012;118:1155-68.

6. Fisher R, Pusztai L, Swanton C. Cancer heterogeneity: implications for targeted therapeutics. Br J Cancer. 2013;108:479-85.

7. Nowell PC. The clonal evolution of tumor cell populations. Science. 1976;194:23-8

8. Thirlwell C, Will OC, Domingo E, Graham TA, McDonald SA, Oukrif D, et al. Clonality assessment and clonal ordering of individual neoplastic crypts shows polyclonality of colorectal adenomas. Gastroenterology. 2010;138:1441-54

9. Greaves M, Maley CC. Clonal evolution in cancer. Nature. 2012;481:30613.

10. Martinez P, Birkbak NJ, Gerlinger M, McGranahan N, Burrell RA Rowan AJ, et al. Parallel evolution of tumour subclones mimics diversity between tumours. J Pathol. 2013;230:356-64

11. Yachida S, Jones S, Bozic I, Antal T, Leary R, Fu B, et al. Distant metastasis occurs late during the genetic evolution of pancreatic cancer. Nature. 2010;467:1114-7.

12. Gerlinger M, Rowan AJ, Horswell S, Larkin J, Endesfelder D, Gronroos $\mathrm{E}$, et al. Intratumor heterogeneity and branched evolution revealed by multiregion sequencing. N Engl J Med. 2012;366:883-92.

13. Wu X, Northcott PA, Dubuc A, Dupuy AJ, Shih DJ, Witt $H$, et al. Clonal selection drives genetic divergence of metastatic medulloblastoma. Nature. 2012;482:529-33

14. Hanahan $D$, Weinberg RA. Hallmarks of cancer: the next generation. Cell. 2011;144:646-74.

15. Loeb LA. Cancer cells exhibit a mutator phenotype. Adv Cancer Res. 1998;72:25-56.

16. Almendro V, Marusyk A, Polyak K. Cellular heterogeneity and molecular evolution in cancer. Annu Rev Pathol. 2013;8:277-302.

17. Burrell RA, McGranahan N, Bartek J, Swanton C. The causes and consequences of genetic heterogeneity in cancer evolution. Nature. 2013;501:338-45

18. Junttila MR, de Sauvage FJ. Influence of tumour micro-environment heterogeneity on therapeutic response. Nature. 2013;501:346-54

19. Fridman WH, Pages F, Sautes-Fridman C, Galon J. The immune contexture in human tumours: impact on clinical outcome. Nat Rev Cancer. 2012;12:298-306.

20. Marusyk A, Almendro V, Polyak K. Intra-tumour heterogeneity: a looking glass for cancer? Nat Rev Cancer. 2012;12:323-34

21. Vermaat JS, Nijman IJ, Koudijs MJ, Gerritse FL, Scherer SJ, Mokry M, et al. Primary colorectal cancers and their subsequent hepatic metastases are genetically different: implications for selection of patients for targeted
Research and Ethics Committee and to the Helsinki Declaration of the World Medical Association.

\section{DATA CONFIDENTIALITY}

The authors declare having followed the protocols in use at their working center regarding patient's data publication.

\section{CONFLICTS OF INTEREST}

The authors declare that there are no conflicts of interest.

\section{FUNDING SOURCES}

No subsidies or grants contributed to this work.

treatment. Clin Cancer Res. 2012:18:688-99.

22. Place AE, Jin Huh S, Polyak K. The microenvironment in breast cancer progression: biology and implications for treatment. Breast Cancer Res. 2011;13:227.

23. Tlsty TD, Coussens LM. Tumor stroma and regulation of cancer development. Annu Rev Pathol. 2006;1:119-50.

24. Ohuchida K, Mizumoto K, Murakami M, Qian LW, Sato N, Nagai $E$, et al. Radiation to stromal fibroblasts increases invasiveness of pancreatic cancer cells through tumor-stromal interactions. Cancer Res. 2004;64:3215-22.

25. Inda MM, Bonavia R, Mukasa A, Narita Y, Sah DW, Vandenberg S, et al Tumor heterogeneity is an active process maintained by a mutant EGFRinduced cytokine circuit in glioblastoma. Genes Dev. 2010;24:1731-45.

26. Tredan O, Galmarini CM, Patel K, Tannock IF. Drug resistance and the solid tumor microenvironment. J Natl Cancer Inst. 2007;99:1441-54.

27. Des Guetz G, Uzzan B, Nicolas P, Cucherat M, Morere JF, Benamouzig $\mathrm{R}$, et al. Microvessel density and VEGF expression are prognostic factors in colorectal cancer. Meta-analysis of the literature. $\mathrm{Br} \mathrm{J}$ Cancer. 2006;94:1823-32

28. Mao Q, Zhang Y, Fu X, Xue J, Guo W, Meng M, et al. A tumor hypoxic niche protects human colon cancer stem cells from chemotherapy. J Cancer Res Clin Oncol. 2013;139:211-22.

29. Lu J, Ye X, Fan F, Xia L, Bhattacharya R, Bellister S, et al. Endothelia cells promote the colorectal cancer stem cell phenotype through a soluble form of Jagged-1. Cancer Cell. 2013;23:171-85.

30. Hurwitz HI, Fehrenbacher L, Hainsworth JD, Heim W, Berlin J, Holmgren $\mathrm{E}$, et al. Bevacizumab in combination with fluorouracil and leucovorin: an active regimen for first-line metastatic colorectal cancer. J Clin Oncol. 2005;23:3502-8

31. Fadhil W, Ibrahem S, Seth R, AbuAli G, Ragunath K, Kaye P, et al. The utility of diagnostic biopsy specimens for predictive molecular testing in colorectal cancer. Histopathology. 2012;61:1117-24.

32. Krol LC, Hart NA, Methorst N, Knol AJ, Prinsen C, Boers JE. Concordance in KRAS and BRAF mutations in endoscopic biopsy samples and resection specimens of colorectal adenocarcinoma. Eur J Cancer. 2012;48:1108-15

33. Richman SD, Chambers P, Seymour MT, Daly C, Grant S, Hemmings G, et al. Intra-tumoral heterogeneity of KRAS and BRAF mutation status in patients with advanced colorectal cancer (aCRC) and cost-effectiveness of multiple sample testing. Anal Cell Pathol. 2011;34:61-6.

34. Noterdaeme O, Kelly M, Friend P, Soonowalla Z, Steers G, Brady M. Initial assessment of a model relating intratumoral genetic heterogeneity to radiological morphology. Br J Radiol. 2010;83:166-70.

35. Baldus SE, Schaefer KL, Engers $R$, Hartleb $D$, Stoecklein $N H$, Gabbert HE. Prevalence and heterogeneity of KRAS, BRAF, and PIK3CA mutations in primary colorectal adenocarcinomas and their corresponding metastases. Clin Cancer Res. 2010;16:790-9.

36. Miranda E, Bianchi P, Destro A, Morenghi E, Malesci A, Santoro A, et al. Genetic and epigenetic alterations in primary colorectal cancers and related lymph node and liver metastases. Cancer. 2013;119:266-76.

37. Bedard PL, Hansen AR, Ratain MJ, Siu LL. Tumour heterogeneity in the clinic. Nature. 2013;501:355-64.

38. Messersmith WA, Ahnen DJ. Targeting EGFR in colorectal cancer. N Engl J Med. 2008;359:1834-6. 
39. Lievre A, Bachet JB, Le Corre D, Boige V, Landi B, Emile JF, et al. KRAS mutation status is predictive of response to cetuximab therapy in colorectal cancer. Cancer Res. 2006;66:3992-5.

40. Lievre A, Bachet JB, Boige V, Cayre A, Le Corre D, Buc E, et al. KRAS mutations as an independent prognostic factor in patients with advanced colorectal cancer treated with cetuximab. J Clin Oncol. 2008;26:374-9.

41. Di Fiore F, Blanchard F, Charbonnier F, Le Pessot F, Lamy A, Galais $\mathrm{MP}$, et al. Clinical relevance of KRAS mutation detection in metastatic colorectal cancer treated by Cetuximab plus chemotherapy. $\mathrm{Br} \mathrm{J}$ Cancer. 2007;96:1166-9.

42. Khambata-Ford S, Garrett CR, Meropol NJ, Basik M, Harbison CT, Wu $\mathrm{S}$, et al. Expression of epiregulin and amphiregulin and K-ras mutation status predict disease control in metastatic colorectal cancer patients treated with cetuximab. J Clin Oncol. 2007;25:3230-7.

43. De Roock W, Piessevaux H, De Schutter J, Janssens M, De Hertogh $\mathrm{G}$, Personeni $\mathrm{N}$, et al. KRAS wild-type state predicts survival and is associated to early radiological response in metastatic colorectal cancer treated with cetuximab. Ann Oncol. 2008;19:508-15.

44. Saltz LB, Meropol NJ, Loehrer PJ Sr., Needle MN, Kopit J, Mayer RJ. Phase II trial of cetuximab in patients with refractory colorectal cancer that expresses the epidermal growth factor receptor. J Clin Oncol. 2004;22:1201-8.

45. Hecht JR, Mitchell E, Neubauer MA, Burris HA 3rd, Swanson P, Lopez $\mathrm{T}$, et al. Lack of correlation between epidermal growth factor receptor status and response to panitumumab monotherapy in metastatic colorectal cancer. Clin Cancer Res. 2010;16:2205-13.

46. Chung KY, Shia J, Kemeny NE, Shah M, Schwartz GK, Tse A, et al. Cetuximab shows activity in colorectal cancer patients with tumors that do not express the epidermal growth factor receptor by immunohistochemistry. J Clin Oncol. 2005;23:1803-10.

47. Stoecklein NH, Klein CA. Genetic disparity between primary tumours, disseminated tumour cells, and manifest metastasis. Int $\mathrm{J}$ Cancer. 2010;126:589-98.

48. Knijn N, Mekenkamp LJ, Klomp M, Vink-Borger ME, Tol J, Teerenstra S, et al. KRAS mutation analysis: a comparison between primary tumours and matched liver metastases in 305 colorectal cancer patients. $\mathrm{Br} \mathrm{J}$ Cancer. 2011;104:1020-6.
49. Park JH, Han SW, Oh DY, Im SA, Jeong SY, Park KJ, et al. Analysis of KRAS, BRAF, PTEN, IGF1R, EGFR intron 1 CA status in both primary tumors and paired metastases in determining benefit from cetuximab therapy in colon cancer. Cancer Chemother Pharmacol. 2011;68:104555.

50. Vakiani E, Janakiraman M, Shen R, Sinha R, Zeng Z, Shia J, et al. Comparative genomic analysis of primary versus metastatic colorectal carcinomas. J Clin Oncol. 2012;30:2956-62.

51. Italiano A, Hostein I, Soubeyran I, Fabas T, Benchimol D, Evrard S, et al. KRAS and BRAF mutational status in primary colorectal tumors and related metastatic sites: biological and clinical implications. Ann Surg Oncol. 2010;17:1429-34.

52. Etienne-Grimaldi MC, Formento JL, Francoual M, Francois E, Formento $\mathrm{P}$, Renee $\mathrm{N}$, et al. K-Ras mutations and treatment outcome in colorectal cancer patients receiving exclusive fluoropyrimidine therapy. Clin Cancer Res. 2008;14:4830-5.

53. Diaz LA Jr, Williams RT, Wu J, Kinde I, Hecht JR, Berlin J, et al. The molecular evolution of acquired resistance to targeted EGFR blockade in colorectal cancers. Nature. 2012;486:537-40.

54. Misale S, Yaeger R, Hobor S, Scala E, Janakiraman M, Liska D, et al. Emergence of KRAS mutations and acquired resistance to anti-EGFR therapy in colorectal cancer. Nature. 2012;486:532-6.

55. Molinari F, Felicioni L, Buscarino M, De Dosso S, Buttitta F, Malatesta S, et al. Increased detection sensitivity for KRAS mutations enhances the prediction of anti-EGFR monoclonal antibody resistance in metastatic colorectal cancer. Clin Cancer Res. 2011;17:4901-14.

56. Zielinski C, Knapp S, Mascaux C, Hirsch F. Rationale for targeting the immune system through checkpoint molecule blockade in the treatment of non-small-cell lung cancer. Ann Oncol. 2013;24:1170-9.

57. Russnes HG, Navin N, Hicks J, Borresen-Dale AL. Insight into the heterogeneity of breast cancer through next-generation sequencing. $J$ Clin Invest. 2011;121:3810-8.

58. Gargis AS, Kalman L, Berry MW, Bick DP, Dimmock DP, Hambuch $\mathrm{T}$, et al. Assuring the quality of next-generation sequencing in clinical laboratory practice. Nat Biotechnol. 2012;30:1033-6.

59. Meacham CE, Morrison SJ. Tumour heterogeneity and cancer cell plasticity. Nature. 2013;501:328-37. 
Rui BARRANHA, José Luís COSTA, Fátima CARNEIRO, José Carlos MACHADO

\section{Genetic Heterogeneity in Colorectal Cancer and its Clinical Implications}

Acta Med Port 2015:28:370-375

Publicado pela Acta Médica Portuguesa, a Revista Científica da Ordem dos Médicos

Av. Almirante Gago Coutinho, 151

1749-084 Lisboa, Portugal.

Tel: +351218428 215

E-mail: submissao@actamedicaportuguesa.com

www.actamedicaportuguesa.com

ISSN:0870-399X | e-ISSN: 1646-0758

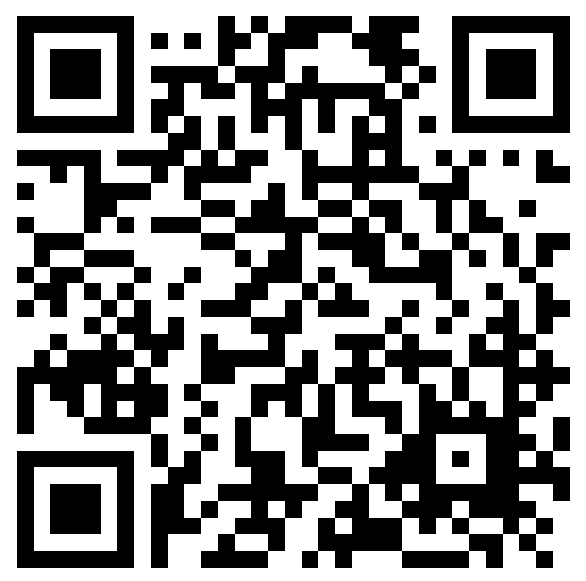

